\title{
EDITORIAL
}

\section{Plus ça change}

\author{
Miranda Robertson
}

This month, the two flagship biology journals of BioMed Central, Journal of Biology and BMC Biology, join forces under the title $B M C$ Biology, as a journal whose aim is to maintain and develop the strengths of both. We have chosen the title BMC Biology not as a signal of the predominance of that journal over Journal of Biology, but to affirm the connection of the fused publication with BioMed Central, and its close relationship with its sibling journals of the BMC series (see [1]). But we like the genetic principle of codominance; and of course hybrid vigor.

That said, the fused publication will look and behave more like Journal of Biology than BMC Biology in most ways. We shall continue to publish the topical and authoritative review and comment that have regularly appeared in Journal of Biology, which will also bring its publication policy and speed of response to the fused journal (more on policy below). But listing on the Web of Science and Journal Citation Record will be as BMC Biology.

In combining two journals, we are swimming against the tide of ever-proliferating new journals, a point remarked by Gregory Petsko in a Comment [2] written for us to mark the occasion and in which, with the verve and effrontery with which regular readers of his column in our sister journal Genome Biology will be familiar, he deplores such proliferation - inviting, perhaps, dissent. But we agree of course that this particular fusion is rational.

In the combined journal, what is new, and what is not?

\section{What's new}

To launch the new BMC Biology, we are publishing the first in an occasional series of special question-andanswer features, in which we invite biologists with a strong personal view on a subject of topical interest or fundamental importance to record a video interview which is posted online with the edited text, and so can be viewed or read, or both, according to preference. Our first interviewee is Martin Raff, the founding Editor-inChief of Journal of Biology and member of the Editorial Board of the fused journal. He speaks on autism [3], in which he developed a passionate interest when his

*Correspondence: bmcbiologyeditorial@biomedcentral.com

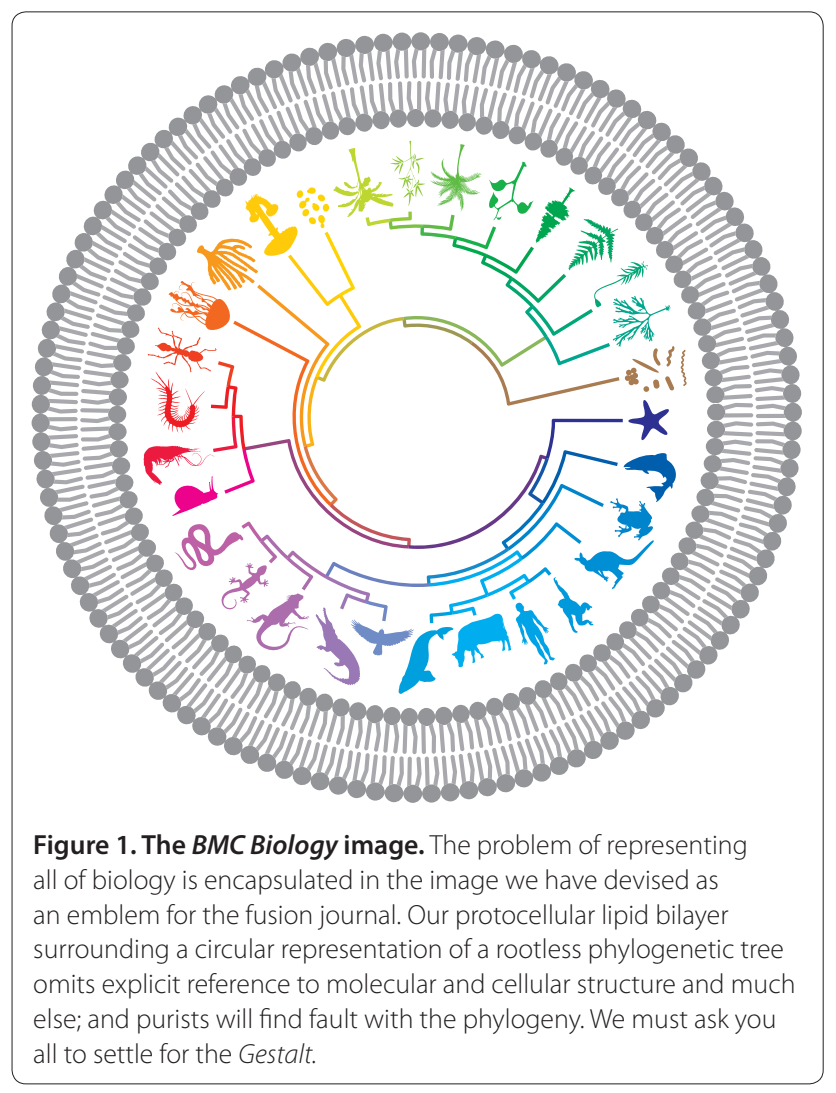

grandson was diagnosed at a year and a half as autistic, and tackles issues ranging from the promise of genomic and induced stem cell technologies to the reasons for the apparent increase in incidence.

The next Video Q\&A, to be posted in May, will be from John Mattick, on the importance and roles of noncoding RNA - just as passionate, and - at least as concerns his perspective on biology - just as personal.

We also have a new emblematic image (Figure 1).

\section{What's not}

BMC Biology and Journal of Biology between them have been committed to the publication of biological research papers of sufficient interest or importance to justify drawing them to the attention of a broad general readership, and papers selected for publication in the fusion journal will reflect, by and large, the selection criteria of 
both parents, so that the range of papers published will be greater than for either.

But although some papers are undoubtedly more worthy of general attention than others, biology, in the main, has become so specialized, and biologists so focused, that there are few research papers that can be comfortably read, still less properly appreciated, by people much outside their immediate field. Journal of Biology has addressed this paradox of the so-called general journal by publishing short commentaries, which it has called minireviews, with two functions. For those papers selected for publication in the journal for their exceptional interest or importance, it has published a commentary explaining the significance of the paper for nonspecialists. Papers making a significant but less striking contribution, including not only many published by $B M C$ Biology, but also a selection of those published in other journals published by BioMed Central, have been the stimulus for minireviews giving a more general perspective on the issues they reflect or address. This will continue in the new BMC Biology, except that the two functions of the minireviews will be explicit in two different names: those on papers of exceptional interest will be called 'Focus', and those with a broader remit will be called 'Commentary'.

\section{More of the same, with an experimental twist}

Journal of Biology will also bring to the fusion its policy (already shared in part with BMC Biology) of taking advice from Editorial Board members on the suitability in principle of submitted papers for the journal before sending them to referees, so that referees are asked to judge only the technical soundness of the paper, and not its level of interest. Authors may, as before, choose to enquire in advance of submission whether their paper will seem as interesting to the journal's advisors and editors as it does to them.

A more unconventional contribution to the editorial policy of the fused journal will be the transfer intact from Journal of Biology of its re-review opt-out experiment [4]. This was conceived to address a widespread disgruntlement with current behavioral tendencies of referees, memorably compared in a Comment article by Virginia Walbot in Journal of Biology [5] to those of pit bulls; and to restore a greater share of the responsibility for the quality of the published paper to its authors. The rationale for and operation of re-review opt-out are explained in the editorial [4] we published when we started the experiment, and I will not recapitulate them in detail here. But the essential point is that when authors revise a paper in response to referees (this applies only to revisions, not to resubmissions), they may choose whether the referees are consulted again before publication. We said we would continue the experiment for as long as it was having no clearly adverse effect on our ability to maintain the quality of published papers. This has not happened to date, and we will report back when that changes, or after six months of experience with the fusion journal, whichever is the sooner.

\section{Hairballs revisited, the hope of progress, and the diversity of Q\&As}

For the inauguration of the Journal of Biology-BMC Biology fusion, we are launching a new series - 'The hope of progress' - on biology relevant to clinical problems. I have already mentioned our Video Q\&A with Martin Raff, which is a special contribution to the series: the two other Hope of progress launch features are reviews on biology-based cancer therapy [6] and on vaccine adjuvants [7], and they are introduced in an accompanying editorial [8], in which some of the issues of psychiatric genomics raised by Martin Raff are briefly discussed.

Our other Q\&A - non-video - is also relevant to psychiatric genomics, but in the broader context of genome-wide association studies (GWAS) in general. In it, John Brookfield explains [9] the genetic and evolutionary principles underlying the current major collaborative efforts to understand what has become known as the genetic architecture of complex diseases, how they can be bedevilled by the structure of populations, and why they may be most successful for the diseases of old age.

Brookfield's Q\&A joins earlier Journal of Biology Q\&As tackling concepts critical to topical issues in modern biology but with which modern biologists are not always wholly at ease (see [10] for a full listing of Journal of Biology Q\&As).

The very first of our Q\&As was from James Ferrell [10], a lively assault on the confusion of the uninitiated about systems biology, and featuring the familiar systems biology hairball (see Figure 1 in [11]) - a representation of nodes and edges with more iconic than explanatory power. In this inaugural collection for the fusion journal, the hairball is revisited (and indeed the same hairball is reproduced) in an article by Arthur Lander [12], the author of one of our most accessed items of 2009 (on the stem cell concept [13]). Ferrell asked "What is systems biology?" Lander can be said to ask rather "Why is systems biology?" - a question that he answers with an eloquent and absorbing disquisition on the absolute necessity of modelling, at all levels, if we wish to advance beyond knowledge to understanding.

\section{Published: 12 April 2010}

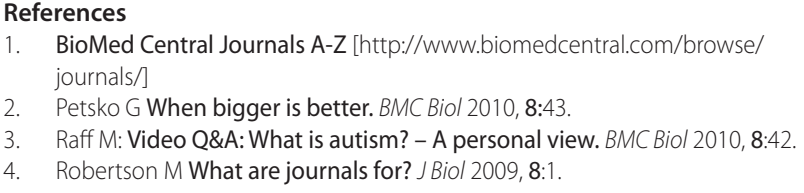


5. Walbot $\vee$ Are we training pit bulls to review our manuscripts? J Biol 2009, 8:24.

6. Lord CJ, Ashworth A: Biology driven cancer drug development: back to the future. BMC Biol 2010, 8:38

7. McKee AS, MacLeod MKL, Kappler JW, Marrack P: Immune mechanisms of protection: can adjuvants rise to the challenge? BMC Bio/ 2010, 8:37.

8. Robertson M The hope of progress. BMC Biol 2010, 8:39.

9. Brookfield JFY: Promise and pitfalls of genome-wide association studies. BMC Biol 2010, 8:41.
10. BMC Biology Q\&As [http://www.biomedcentral.com/series/bmcbiolqanda]

11. Ferrell JE Jr: Q\&A: Systems biology. J Bio/ 2009, 8:2.

12. Lander $A D$ The edges of understanding. BMC Biol 2010, 8:40.

13. Lander AD The 'stem cell' concept: is it holding us back? J Biol 2009, 8:70

doi:10.1186/1741-7007-8-44

Cite this article as: Robertson M: Plus ça change. BMC Biology 2010, 8:44. 